\title{
Outer-membrane-protein subtypes of Haemophilus influenzae isolates from North India
}

\author{
R. Kaur, A. Sharma, S. Majumdar, N. K. Ganguly and A. Chakraborti \\ Department of Experimental Medicine and Biotechnology, Postgraduate Institute of Medical \\ Education and Research, Chandigarh - 160012, India
}

Correspondence

A. Chakraborti

superoxide@sify.com

\begin{abstract}
Haemophilus influenzae serotype b and non-typable isolates from blood, cerebrospinal fluid, sputum and throat swabs of patients and carriers in North India were analysed by outer-membrane protein (OMP) profiling. OMP analysis could differentiate the samples into 18 different subtypes. The non-typable isolates were more variable than the serotype b samples. OMP subtypes 1- 6 were found only among the serotype b isolates and subtypes 7-18 among the non-typable isolates, while subtypes 2 and 8 were exhibited by both. The OMP profiles of isolates from blood, cerebrospinal fluid and sputum are in complete agreement with their ribotypes and RAPD fingerprints. The present study demonstrates for the first time the subtyping of Indian $H$. influenzae isolates by an easy and less-expensive method that is applicable to developing countries like India.
\end{abstract}

Received 23 September 2002

Accepted 28 April 2003
Although their widespread use in affluent countries has resulted in a decline in the incidence rate of Hib infections, there is a growing incidence of infections caused by nontype-b and non-typable strains of $H$. influenzae. Outermembrane proteins (OMP) have been a major focus of research aimed at identifying conserved and antigenic surface components for inclusion in vaccines and for their ability to separate non-typable strains into subtypes corresponding to a particular epidemiological area.

The outer membrane of $H$. influenzae contains about 36 proteins, of which between six and eight make up the major protein content, with the remainder existing as relatively minor proteins (Loeb \& Smith, 1980). The major OMPs include heat-modifiable $47 \mathrm{kDa}$ P1 (Loeb, 1987), $39 \mathrm{kDa}$ P2 porin (Munson et al., 1983), $28 \mathrm{kDa}$ P4 lipoprotein (Green et al., 1991), $37 \mathrm{kDa}$ P5 (Loeb \& Smith, 1980), $16 \mathrm{kDa}$ P6 or peptidoglycan-associated lipoprotein (Munson \& Granoff, 1985) and the high-molecular-mass proteins HMW1 and HMW2 (Noel et al., 1994). The minor OMPs include P6 cross-reacting protein (PCP, $15 \mathrm{kDa}$ ) (Deich et al., 1990), OMP26 (26 kDa) (Kyd \& Cripps, 1998), $80 \mathrm{kDa}$ D15 (Loosmore et al., 1997), $42 \mathrm{kDa}$ protein D (Akkoyunlu et al., 1991), transferrin-binding proteins of 85 and $100 \mathrm{kDa}$ (Schryvers, 1989; Morton \& Williams, 1990), haem:haemopexin-binding protein (Cope et al., 1998), haemoglobin-binding proteins (Ren et al., 1998) and several high-molecular-mass proteins ranging from 120 to $125 \mathrm{kDa}$. Some OMPs are consistently present in all strains of $H$. influenzae, while others vary among the typable and nontypable strains.

The preparation of sarkosyl-insoluble membrane proteins provides purified OMPs (Filip et al., 1973) that form the basis of subtyping schemes defined for $H$. influenzae strains 
(Barenkamp et al., 1981; Granoff et al., 1982; van Alphen et al., 1983). This technique has been shown to be highly discriminatory and has been used with success to investigate putative outbreaks of infection with $H$. influenzae.

Subtyping of the present isolates based on molecular techniques has been reported earlier from our laboratory (Sharma et al., 2002). An alternative to this was sought, since the methods were expensive and their application in a country like ours was not satisfactory. Thus, the present study was intended to subtype $H$. influenzae isolates from India by a less-expensive method based on differences in their OMP patterns.

\section{METHODS}

Study population. A total of $120 \mathrm{H}$. influenzae isolates was obtained from cerebrospinal fluid (CSF), blood, sputum samples and throat swabs of patients and healthy carrier population, of which 77 were Hib and 43 NTHi. Details of patients and numbers of samples screened have been given previously (Sharma et al., 2002). The same samples were used for analysis in the present study.

Bacterial isolates. H. influenzae strains were grown on chocolate agar supplemented with haemin and NAD. The presence or absence of capsular polysaccharide was detected by slide agglutination using antisera to the capsular antigens $\mathrm{a}-\mathrm{f}$ (Difco). Isolates were stored at $-70{ }^{\circ} \mathrm{C}$ in brain heart infusion broth containing $5 \%$ glycerol.

Preparation of OMPs. Outer membranes were prepared by the method of Carlone et al. (1986) with a few modifications. This method involves lysis of the cells by ultrasonication. Chocolate-agar plates were inoculated with strains of $H$. influenzae and incubated so as to obtain $18 \mathrm{~h}$ growth. The growth was harvested with $2 \mathrm{ml} 10 \mathrm{mM}$ HEPES buffer per plate and transferred to centrifuge tubes that were centrifuged at $40000 \mathrm{~g}$ for $30 \mathrm{~min}$. The pellet was resuspended in $10 \mathrm{ml} 10 \mathrm{mM}$ HEPES buffer containing $5 \mathrm{mM}$ PMSF. Sonication was done four or five times in a sonicator for $30 \mathrm{~s}$ with $30 \mathrm{~s}$ breaks in between (in an ice-bath). Intact cells and large debris were removed by centrifugation at $200 \mathrm{~g}$ for $30 \mathrm{~min}$ at $4{ }^{\circ} \mathrm{C}$. The total membrane preparation was harvested from the supernatant by ultracentrifugation at $100000 \mathrm{~g}$ for $1 \mathrm{~h}$ at $4{ }^{\circ} \mathrm{C}$. The clear, gel-like pellet was resuspended in $1 \%$ sodium lauryl sarcosinate in $10 \mathrm{mM}$ HEPES buffer for $30 \mathrm{~min}$ at room temperature and the detergent-insoluble fraction was harvested by centrifugation at $100000 \mathrm{~g}$ at $4{ }^{\circ} \mathrm{C}$ for $1 \mathrm{~h}$. The pellet was washed twice at $100000 \mathrm{~g}$ at $4{ }^{\circ} \mathrm{C}$ for $1 \mathrm{~h}$ in HEPES containing PMSF. After washing, the pellet was suspended in $500 \mu \mathrm{l}$ HEPES with PMSF and $50 \mu \mathrm{l}$ aliquots were stored at $-20{ }^{\circ} \mathrm{C}$.

Separation of proteins by SDS-PAGE. Protein concentrations were estimated by the modified method of Lowry et al. (1951). SDS-PAGE was done by the method of Laemmli (1970) using a discontinuous buffer system with $15 \%(\mathrm{w} / \mathrm{v})$ polyacrylamide as the resolving gel. Samples were prepared by adding $5 \times$ sample buffer to $1 \times$ final concentration and heating in a boiling water bath for $5 \mathrm{~min}$. Lowmolecular-mass standards (Roche) were included with each run. The gel was run at a constant current of $40 \mathrm{~mA}$ until the dye front just reached the bottom. The gel was then fixed in $12 \%$ trichloroacetic acid for 30 min, stained overnight in Coomassie brilliant blue, destained and finally photographed.

\section{RESULTS}

In the present study, the heterogeneity among $H$. influenzae strains prevalent in North India was studied by OMP analysis. A total of 305 CSF samples and 41 blood samples from infants, throat swabs of 63 healthy children and adults and sputum samples from 25 adult patients were screened. Details of the samples and strains obtained were provided previously (Sharma et al., 2002).

The OMP profile for each subtype when examined by SDSPAGE showed 10-22 OMPs with molecular masses of approximately $15-100 \mathrm{kDa}$ (Fig. 1 ). The $28 \mathrm{kDa}$ P4 protein was conserved among both the typable and non-typable isolates, while the $16 \mathrm{kDa} \mathrm{P} 6$ protein, which elicits protective antibody against NTHi and has been reported in the literature to be conserved, was variable. It appears that P6 is present in some strains and absent in few. Several minor OMPs were also present in each subtype. OMP P2 was the most abundant, with a molecular mass of $36-42 \mathrm{kDa}$.

OMP analysis differentiated our set of strains into 18 different subtypes on the basis of variation in the major OMPs, with molecular masses ranging from 25 to $50 \mathrm{kDa}$ and also from 14 to $20 \mathrm{kDa}$ (Fig. 1), based on reproducible and clearly resolvable patterns. Variation in the OMP patterns was observed within and between isolates. Over $50 \%$ of $\mathrm{Hib}$ strains belonged to three predominant subtypes (subtypes 13; Table 1). Subtypes 7-18 were observed among the NTHi strains and subtypes 1-6 were present in Hib strains in our North Indian community. Subtype 8 (Fig. 1, lane 8), with two distinct major OMPs, of 36 and $34 \mathrm{kDa}$, was exhibited by one strain isolated from blood (Hib) and one strain isolated from the throat swab of an adult (NTHi) (Table 1). Similarly, subtype 2 was common to both Hib strains isolated from CSF and NTHi strains isolated from throat swabs of children (Table 1).

In the present study, three Hib strains from blood showed the same subtype (subtype 6); a single Hib isolate from blood showed subtype 8 in OMP profile analysis (Table 1). Though

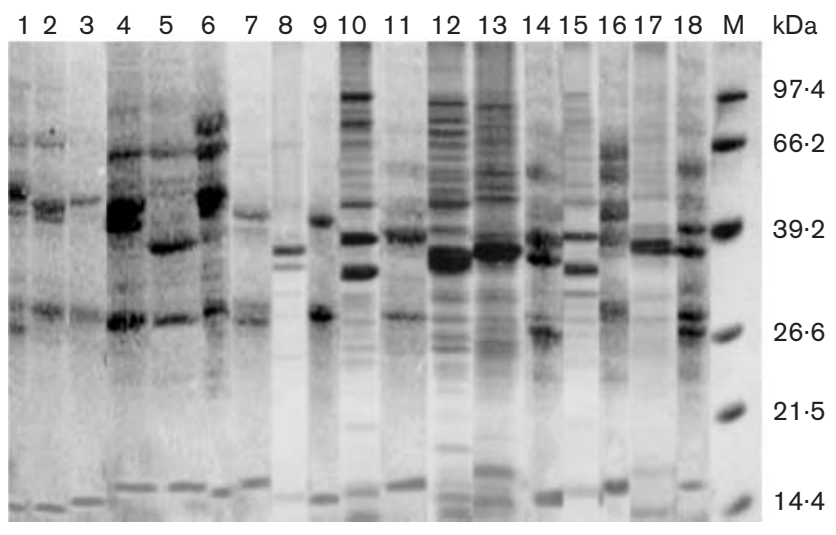

Fig. 1. OMP subtypes of Hib and NTHi isolates. Lane numbers (118) indicate representative OMP subtypes. The subtypes were categorized on the basis of variations in the major OMPs with molecular masses ranging from 25 to $50 \mathrm{kDa}$ and also from 14 to $20 \mathrm{kDa}$. Lane M, molecular mass marker. 
Table 1. Subtype distribution of Indian $H$. influenzae isolates by OMP analysis

All Hib strains were obtained from infants. TS, Throat swab. OMP subtypes correspond to the lanes in Fig. 1.

\begin{tabular}{|c|c|c|c|c|}
\hline \multirow{2}{*}{$\begin{array}{l}\text { OMP } \\
\text { subtype }\end{array}$} & \multicolumn{2}{|c|}{ Hib } & \multicolumn{2}{|c|}{ NTHi } \\
\hline & Source & $\begin{array}{c}\text { No. of } \\
\text { isolates }\end{array}$ & Source & $\begin{array}{l}\text { No. of } \\
\text { isolates }\end{array}$ \\
\hline 1 & CSF & 18 & - & 0 \\
\hline 2 & CSF & 17 & TS child & 2 \\
\hline 3 & CSF & 25 & - & 0 \\
\hline 4 & CSF & 5 & - & 0 \\
\hline 5 & CSF & 8 & - & 0 \\
\hline 6 & Blood & 3 & - & 0 \\
\hline 7 & - & 0 & TS child & 3 \\
\hline 8 & Blood & 1 & TS adult & 1 \\
\hline 9 & - & 0 & TS child & 2 \\
\hline 10 & - & 0 & TS adult & 1 \\
\hline 11 & - & 0 & Sputum & 8 \\
\hline 12 & - & 0 & TS adult & 2 \\
\hline 13 & - & 0 & TS adult & 1 \\
\hline 14 & - & 0 & TS child & 6 \\
\hline 15 & - & 0 & TS adult & 3 \\
\hline 16 & - & 0 & TS child & 9 \\
\hline 17 & - & 0 & TS adult & 2 \\
\hline 18 & - & 0 & TS child & 3 \\
\hline
\end{tabular}

they were from serotype $\mathrm{b}$, the CSF isolates also showed polymorphism. Among the $18 \mathrm{CSF}$ samples of OMP subtype 1 , only six isolates previously showed similar ribotypes and RAPD profiles. Of the NTHi isolates, eight strains isolated from sputum samples of patients with chronic bronchitis (Table 1) exhibited similar profiles (subtype 11) in OMP analysis when examined in SDS-PAGE. However, NTHi isolates from throat swabs of the healthy carrier population were distributed randomly over the various subtypes, as in our previous study.

\section{DISCUSSION}

Our previous study on the epidemiology of $H$. influenzae using molecular approaches showed a high prevalence of infections associated with $H$. influenzae in our community. In the present investigation, we have studied the epidemiology of $H$. influenzae strains by protein-based methods. This is the first report from India regarding $H$. influenzae typing by OMP analysis. Subtyping of $H$. influenzae by protein analysis has been done for strains from North America, Europe and the UK (Pennington \& Freebairn, 1989; Jordens et al., 1993).

OMP analysis differentiated our set of strains into 18 subtypes, suggesting diversity among $H$. influenzae strains in our community. OMP analysis of $H$. influenzae isolates from North America revealed 21 distinct OMP types, with $89 \%$ of strains belonging to only six OMP types, but there was a lack of correlation between OMP profiling and biotyping (Barenkamp et al., 1981). In Western Europe, OMP type 1 is reported to be significantly more common, though OMP 11 was more prevalent in Iceland (van Alphen et al., 1987). Similarly, we also observed some predominant subtypes (1-3) and some subtypes common to Hib and NTHi isolates (2 and 8) (Table 1).

In a study from The Netherlands of $80 \mathrm{H}$. influenzae strains isolated from CSF of patients with meningitis, OMP analysis revealed that $84 \%$ of the isolates had identical major OMP patterns (subtype 1). Of the remaining isolates, four different PAGE patterns were observed, two of which closely resembled subtype 1 (van Alphen et al., 1983). In this study, the OMP patterns observed were based on differences in the position and electrophoretic mobility of the major OMPs a (47 kDa), c (40 kDa), d (37 kDa) and e (30 kDa). The Dutch strains therefore did not show much variability in their OMP patterns. In comparison, our Hib strains from CSF were found to be more heterogeneous and gave five different OMP patterns (Table 1).

A study from Pakistan analysed clonal diversity of 95 Haemophilus isolates from blood of children with lower respiratory tract infection by OMP analysis. Of the $H$. influenzae isolates, 61 (64\%) were Hib and $34(36 \%)$ were NTHi; $95 \%$ of the Hib isolates were members of a single clonal group, as defined by SDS-PAGE OMP profile analysis, multilocus enzyme electrophoresis and biotype analysis. This clone is rarely observed among Hib strains recovered from patients with invasive type-b disease in the USA or Europe. The non-typable isolates from Islamabad were also clonally restricted; nine clonal groups were found among 34 isolates, with just five clonal groups accounting for most $(82 \%)$ of the strains (Weinberg et al., 1989). In contrast, our strains did not reveal any clonal subtype by OMP analysis.

Our study has also shown that the NTHi strains prevalent in our community have diverse OMP profiles, which suggests that NTHi strains are more heterogeneous in nature compared with Hib strains. A study by Aparicio et al. (1996) also showed that Hib strains had a strong clonal structure, in contrast to NTHi strains. Hib strains showed one pattern with isoenzymes, OMP and ribotyping techniques. Only PFGE allowed differentiation between several Hib patterns, although all of them were closely related. All methods showed a great variety of patterns with NTHi strains.

An important finding of our study is that isolates from blood, CSF and sputum samples of patients showed complete agreement in their profiles produced by molecular approaches (Sharma et al., 2002) and OMP analysis. In the OMP analysis, the same three isolates from blood that presented ribotype A with EcoRI and RAPD type a with primers AP1 and AP2 in our previous study showed OMP subtype 6 , while the strain of ribotype D and RAPD type d showed OMP subtype 8. Six of the Hib isolates from CSF samples that gave ribotype A with EcoRI and HaeIII and RAPD type a with both primers clustered into OMP subtype 1. Among the NTHi isolates, OMP subtype 11 was generated 
by all eight isolates from sputum samples of patients with chronic bronchitis that were of ribotype A with HaeIII and RAPD types $g$ and $k$ with primers AP1 and AP2, respectively. Therefore, OMP subtyping, which is cheaper, reproducible and more sensitive to strain variations, provides an important tool for epidemiological studies in developing countries such as India.

\section{REFERENCES}

Akkoyunlu, M., Ruan, M. \& Forsgren, A. (1991). Distribution of protein $\mathrm{D}$, an immunoglobulin D-binding protein, in Haemophilus strains. Infect Immun 59, 1231-1238.

Aparicio, P., Roman, F. \& Campos, J. (1996). Epidemiological characterization of Haemophilus influenzae using molecular markers. Enferm Infec Microbiol Clin 14, 227-232.

Barenkamp, S. J., Munson, R. S., Jr \& Granoff, D. M. (1981). Subtyping isolates of Haemophilus influenzae type b by outer-membrane protein profiles. J Infect Dis 143, 668-676.

Carlone, G. M., Thomas, M. L., Rumschlag, H. S. \& Sottnek, F. O. (1986). Rapid microprocedure for isolating detergent-insoluble outer membrane proteins from Haemophilus species. J Clin Microbiol 24, 330-332.

Cope, L. D., Thomas, S. E., Hrkal, Z. \& Hansen, E. J. (1998). Binding of heme-hemopexin complexes by soluble HxuA protein allows utilization of this complexed heme by Haemophilus influenzae. Infect Immun 66, 4511-4516.

Deich, R. A., Anilionis, A., Fulginiti, J., Metcalf, B. J., Quataert, S., QuinnDey, T., Zlotnick, G. W. \& Green, B. A. (1990). Antigenic conversation of the 15,000-dalton outer membrane lipoprotein PCP of Haemophilus influenzae and biologic activity of anti-PCP antisera. Infect Immun 58, $3388-3393$.

Filip, C., Fletcher, G., Wulff, J. L. \& Earhart, C. F. (1973). Solubilization of the cytoplasmic membrane of Escherichia coli by the ionic detergent sodium-lauryl sarcosinate. J Bacteriol 115, 717-722.

Granoff, D. M., Barenkamp, S. J. \& Munson, R. S., Jr (1982). Outer membrane protein subtypes for epidemiological investigation of Haemophilus influenzae type b disease. In Haemophilus influenzae, Epidemiology, Immunology, and Prevention of Disease, pp. 43-54. Edited by S. H. Sell \& P. F. Wright. New York: Elsevier.

Green, B. A., Farley, J. E., Quinn-Dey, T., Deich, R. A. \& Zlotnick, G. W. (1991). The e (P4) outer membrane protein of Haemophilus influenzae: biologic activity of anti-e serum and cloning and sequencing of the structural gene. Infect Immun 59, 3191-3198.

John, T. J., Cherian, T. \& Raghupathy, P. (1998). Haemophilus influenzae disease in children in India: a hospital perspective. Pediatr Infect Dis $J 17$ (Suppl. 9), S169-S171.

Jordens, J. Z., Leaves, N. I., Anderson, E. C. \& Slack, M. P. E. (1993). Polymerase chain reaction-based strain characterization of noncapsulate Haemophilus influenzae. J Clin Microbiol 31, 2981-2987.

Kyd, J. M. \& Cripps, A. W. (1998). Potential of a novel protein, OMP26, from nontypeable Haemophilus influenzae to enhance pulmonary clearance in a rat model. Infect Immun 66, 2272-2278.

Laemmli, U. K. (1970). Cleavage of structural proteins during the assembly of the head of bacteriophage T4. Nature 227, 680-685.
Loeb, M. R. (1987). Protection of infant rats from Haemophilus influenzae type $\mathrm{b}$ infection by antiserum to purified outer membrane protein a. Infect Immun 55, 2612-2618.

Loeb, M. R. \& Smith, D. H. (1980). Outer membrane protein composition in disease isolates of Haemophilus influenzae: pathogenic and epidemiological implications. Infect Immun 30, 709-717.

Loosmore, S. M., Yang, Y. P., Coleman, D. C., Shortreed, J. M., England, D. M. \& Klein, M. H. (1997). Outer membrane protein D15 is conserved among Haemophilus influenzae species and may represent a universal protective antigen against invasive disease. Infect Immun 65, 3701-3707.

Lowry, O. H., Rosebrough, N. J., Farr, A. L. \& Randall, R. J. (1951). Protein measurement with folin-phenol reagent. J Biol Chem 193, 265-275.

Morton, D. J. \& Williams, P. (1990). Siderophore-independent acquisition of transferrin-bound iron by Haemophilus influenzae type b. J Gen Microbiol 136, 927-933.

Munson, R. S., Jr \& Granoff, D. M. (1985). Purification and partial characterization of outer membrane proteins P5 and P6 from Haemophilus influenzae type b. Infect Immun 49, 544-549.

Munson, R. S., Jr, Shenep, J. L., Barenkamp, S. J. \& Granoff, D. M. (1983). Purification and comparison of outer membrane protein P2 from Haemophilus influenzae type b isolates. J Clin Invest 72, 677-684.

Noel, G. J., Love, D. C. \& Mosser, D. M. (1994). High-molecular-weight proteins of nontypeable Haemophilus influenzae mediate bacterial adhesion to cellular proteoglycans. Infect Immun 62, 4028-4033.

Pennington, T. H. \& Freebairn, E. M. (1989). Subtyping of Haemophilus influenzae type b strains from Europe and North America by SDS-PAGE of whole-cell peptides: the geographical distribution of subtypes. Epidemiol Infect 102, 11-19.

Ren, Z., Jin, H., Morton, D. J. \& Stull, T. L. (1998). $h g p B$, a gene encoding a second Haemophilus influenzae hemoglobin- and hemoglobin-haptoglobin-binding protein. Infect Immun 66, 4733-4741.

Schryvers, A. B. (1989). Identification of the transferrin- and lactoferrin-binding proteins in Haemophilus influenzae. J Med Microbiol 29, $121-130$

Sharma, A., Kaur, R., Ganguly, N. K., Singh, P. D. \& Chakraborti, A (2002). Subtype distribution of Haemophilus influenzae isolates from North India. J Med Microbiol 51, 399-404.

St Geme, J. W., III (1996). Progress towards a vaccine for nontypable Haemophilus influenzae. Ann Med 28, 31-37.

Turk, D. C. (1984). The pathogenicity of Haemophilus influenzae. J Med Microbiol 18, 1-16.

van Alphen, L., Riemens, T., Poolman, J., Hopman, C. \& Zanen, H. C. (1983). Homogeneity of cell envelope protein subtypes, lipopolysaccharides, serotypes, and biotypes among Haemophilus influenzae type b from patients with meningitis in The Netherlands. J Infect Dis 148, $75-81$.

van Alphen, L., Geelen, L., Jonsdottir, K., Takala, A. K., Kayhty, H. \& Zanen, H. C. (1987). Distinct geographic distribution of subtypes of Haemophilus influenzae type b in Western Europe. J Infect Dis 156, 216-218.

Weinberg, G. A., Ghafoor, A., Ishaq, Z. \& 8 other authors (1989). Clonal analysis of Haemophilus influenzae isolated from children from Pakistan with lower respiratory tract infections. J Infect Dis 160, 634-643. 